\title{
ANALYSIS OF SETTLEMENT BEHAVIOUR OF SOFT GROUND UNDER WIDE
} EMBANKMENT

\author{
XIN JIANG ${ }^{*}$, XIAOLI CHEN, YONGGUO FU, \\ HANYAN GU, JINMING HU, XING QIU, YANJUN QIU \\ School of Civil Engineering, Southwest Jiaotong University, Chengdu, China \\ MOE Key Laboratory of High-Speed Railway Engineering, \\ Southwest Jiaotong University, Chengdu, China \\ Highway Engineering Key Laboratory of Sichuan Province, \\ Southwest Jiaotong University, Chengdu, China
}

Received 9 October 2020; accepted 6 May 2021

\begin{abstract}
An elastoplastic numerical model for calculating the consolidation settlement of wide embankment on soft ground is established using PLAXIS finite element software to investigate the settlement behaviour of soft ground under the wide embankment. The distribution rules are analysed and compared to narrow embankments, such as surface settlements of ground and embankment, lateral displacement of soft ground at the foot of embankment slope and excess pore pressure in soft ground. The influence rule of elastic modulus of soft ground on the settlement of soft ground under wide
\end{abstract}

* Corresponding author. E-mail: xjiang01@swjtu.edu.cn

Xin JIANG (ORCID ID 0000-0002-3044-5495)

Xiaoli CHEN (ORCID ID 0000-0002-0661-7955)

Yongguo FU (ORCID ID 0000-0003-1416-5992)

Hanyan GU (ORCID ID 0000-0003-2881-6282)

Jinming HU (ORCID ID 0000-0003-0901-6132)

Xing QIU (ORCID ID 0000-0002-7581-2324)

Yanjun QIU (ORCID ID 0000-0002-2250-5363) 
THE BALTIC JOURNAL

OF ROAD

AND BRIDGE

ENGINEERING

$2021 / 16(4)$

embankment is discussed. The results show that the settlement distributions of wide and narrow embankments on soft ground are "W" and "V" shapes, respectively. The maximum settlement of wide embankment is near the foot of the embankment slope, which is unequal to the settlement at the centreline of the embankment. The lateral displacement distribution rules of soft ground are both "belly" shaped at the foot of two types of embankments slope. However, the lateral displacement of the wide embankment is larger in each corresponding stage. During the construction period, the excess pore pressure in the soft ground under the wide embankment is much higher than that of the narrow embankment, so the post-construction consolidation time of the wide embankment is longer. Moreover, the macroscopic settlement rule of the wide embankment is still the same with the increase of elastic modulus of soft ground.

Keywords: finite element method (FEM), one-dimensional compression, settlement, soft ground, wide embankment.

\section{Introduction}

With the rapid economic development of many countries, the traffic volume increases rapidly. The expressways with eight lanes or even above ten lanes have become more popular to meet the demand of increasing traffic volume. The width of the embankment surface reaches tens or even hundreds of meters, requiring highway engineers to pay more attention to the wide embankment. Two ways are adopted to build a wide embankment, i.e., one way is to widen the existing narrow embankment (Allersma et al., 1994; Lu et al., 2020). Many researchers have paid attention to it at present. The theoretical research is relatively mature, especially in ground improvements for reducing differential settlement between new and existing embankment, including gapmethod (Van Meurs et al., 1999), foundation columns (Han et al., 2007), prefabricated vertical drains (PVD) and dry jet mixing (DJM) columns (Jiang et al., 2020). The other is to construct an entirely new wide embankment directly. Therefore, the new wide embankment has no restraint and influence from the adjacent existing embankment, so the settlement characteristics are different from that of the widened embankment (Jiang et al., 2015).

Moreover, suppose a new wide embankment is designed and constructed directly on soft ground. Attention should be paid to the serious weakness, high compressibility and low permeability of the soft soil. In addition, problems such as large area, large filling, colossal investment, excess settlement and deformation of embankment, intolerable stability and safety also need attention (Gates, 1968). The economic losses and social impacts are concerning once severe 
Xin Jiang, Xiaoli Chen,

Yongguo $\mathrm{Fu}$,

Hanyan Gu,

Jinming Hu, Xing Qiv,

Yanjun Qiu

Analysis

of Settlement

Behaviour

of Soft Ground

under Wide

Embankment industries. Under the previous investigation (Jiang et al., 2019), the wide embankment of highway industry is mainly used in multi-lane expressways, such as Shuijing-Guanjingtou Expressway in Shenzhen, China (the first two-way 10-lane expressway in China), XiamenZhangzhou Intra-City Avenue (the main road with eight lanes and the auxiliary road with six lanes in both directions, the highway with the maximum number of lanes without viaduct in Fujian Province, China). For the railway industry, the width of the embankment section is generally narrow. The wide embankment mainly exists in the station yard, such as Jinan West Passenger Station of Beijing-Shanghai High-speed Railway (3000 m in length, $200 \mathrm{~m}$ in width of the central embankment, and deep soft soil distributed in the range of the station yard). The wide embankment of metro and other urban rail transit projects is mainly distributed in vehicle depots, such as Guangzhou Metro Vehicle Depot. The soft soil thickness of the construction site is generally $2-14 \mathrm{~m}$, the maximum thickness is $17 \mathrm{~m}$, and the width of the embankment is generally $52-72 \mathrm{~m}$. At the same time, due to the characteristics of wide-body aircraft, a lot of wide embankments are distributed in the airport industry, including runway, taxiway, parking apron, such as Shenzhen Airport (with a side length of above $400 \mathrm{~m}$ and a soft soil thickness of 4-6 m).

Stability checking, settlement calculation, ground treatment and impact on surroundings by lateral and vertical deformation are the main design tasks of embankment constructed on soft ground. From the perspective of technical specifications of the highway industry, JTG B012014 Technical Standard of Highway Engineering (Highway Bureau of the Ministry of Transport of the People's Republic of China \& C C C C First Highway Consultants Co., Ltd, 2014) of China does not specify the width of highway embankment when the number of lanes exceeds eight lanes. Thus, it is unable to provide practical technical standards for the design and construction of such a wide embankment. There are special chapters about embankment design on soft ground in China specifications, such as JTG/T D31-02-2013 Technical Guidelines for Design and Construction of Highway Embankment on Soft Ground (C C C C First Highway Consultants Co., Ltd, 2013) and JTG D30-2015 Specifications for Design of Highway Subgrades (C C C C Second Highway Consultants Co., Ltd, 2015). However, these specifications do not answer whether and how the mechanical behaviour and design technology of the embankment will change 
THE BALTIC JOURNAL

OF ROAD

AND BRIDGE

ENGINEERING

$2021 / 16(4)$

fundamentally when the width of the embankment reaches a specific value.

Realising the challenges of constructing a new wide embankment on soft ground, many researchers attempt to explore the settlement behaviour based on field observation or model tests. The $9^{\text {th }}$ contract segment of Xinxiang-Zhengzhou segment of Beijing-Zhuhai Expressway distributes mainly silty clay and silt. Among them, the total width of the embankment surface is $99.0 \mathrm{~m}$, treated by mixing piles for $\mathrm{K} 60+430$ and the total width of the embankment surface is $36.0 \mathrm{~m}$, treated by gravel piles for FK0+190. The field deformation observations of the two sections show that the ground settlement patterns of wide and narrow embankments are different, which are saddle-shaped and parabolicshaped, respectively (Huang \& Zhang, 2007). Jinan West Passenger Station of Beijing-Shanghai High-Speed Railway is $3000 \mathrm{~m}$ in length, $200 \mathrm{~m}$ in width of the central embankment, and the deep soft soil is distributed in the range of the station yard, treated by cement fly-ash gravel (CFG) piles. Field tests indicate two large settlement areas, which are located in the centreline and near the slope foot of wide embankment (Luan et al., 2014). When the soft soil strata with $6 \mathrm{~m}$ thickness is treated by prefabricated vertical drains (PVD) with spacing $1.5 \mathrm{~m}$ and dry jet mixing (DJM) columns with spacing $1.7 \mathrm{~m}$ respectively, the centrifugal model tests of the ultra-wide embankment at Guangzhou Metro Vehicle Depot illustrate that the differences among the centreline and maximum settlements will reach $25 \mathrm{~cm}$ and $4.3 \mathrm{~cm}$ (Shen, 1992). Field tests of Shenzhen airport platform (bagged sand well treatment area $179000 \mathrm{~m}^{2}$, side length above $400 \mathrm{~m}$, soft soil thickness 4-6 m) observe that the monitoring ground settlement is larger in the shoulder area but smaller and relatively uniform in the centre area (Wang \& Xiong, 1992; Zhang, 1999).

Considering the safe implementation of the practical project, the ground of most of the tested sites mentioned above is treated. However, the project of untreated ground is the premise of subsequent scientific design. At the same time, the measurements are more demanding and expensive, such as long measure period, complex organisation and implementation, so numerical methods become more popular to predict the behaviour of embankments on soft ground. Some researchers conducted a related preliminary study on the wide embankment of untreated soft ground. However, the finite element models established are coarse, including constitutive models used and numerical techniques adopted. For example, the constitutive model was ideal linear elastic (Chen et al., 2003; Jiang et al., 2006) or nonlinear elastic (Mao \& Qiu, 2012). Chen and Shi (2006) ignored the post-construction settlement and lateral displacement changes and could not simulate the whole 
consolidation process. The embankment was regarded as a load only, and the interaction and coordinated deformation between embankment and ground were ignored (Chen et al., 2003). Jiang et al. (2015) ignored the change of permeability coefficient in the consolidation process of soft ground. Suppose the constitutive models and parameters used and the numerical techniques adopted, such as applying embankment load and simulating permeability variation of soft ground, are inappropriate. In that case, the accuracy of finite element analysis of soft soil embankment is naturally questionable (Chai \& Bergado, 1993).

Based on the previous work, it is easy to see that there are obvious deficiencies in the deep theoretical research of new wide embankment on soft ground, and the theoretical research lags far behind the engineering practice. Because of this, the paper uses PLAXIS V8.2, a finite element software specialising in geotechnical engineering, to explore the settlement characteristics of the wide embankment on soft ground in an all-around way and whole process. The differences in settlement behaviour between wide and narrow embankments are compared to provide practical guidance for the design and construction of the wide embankment.

\section{Establishment of finite element model}

\subsection{Geometry model}

The subsoil consists of $14 \mathrm{~m}$ of untreated silty clay, and $5 \mathrm{~m}$ of dense sand lowers it in the model (Jiang et al., 2020). The embankment height is $4 \mathrm{~m}$. The slope gradient is $1: 1.5$. The embankment width is $45 \mathrm{~m}$ and $12 \mathrm{~m}$, respectively, which corresponds to the two-way eight-lane embankment of the expressway and the two-way two-lane embankment of the second-class highway in China. Based on the previous study about the identification method of one-dimensional compression zone range (Gan, 2006; Zhang, 1999), the embankments with width $45 \mathrm{~m}$ and $12 \mathrm{~m}$ are determined as wide and narrow embankments, respectively. The problem is symmetric, so only one half is modelled (the right half is chosen). Figure 1 shows the cross-sections of both types of embankments considered as a plane strain problem.
Yanjun Qiu

Analysis of Settlement Behaviour of Soft Ground under Wide Embankment 
a) wide embankment (embankment width - 45 m)

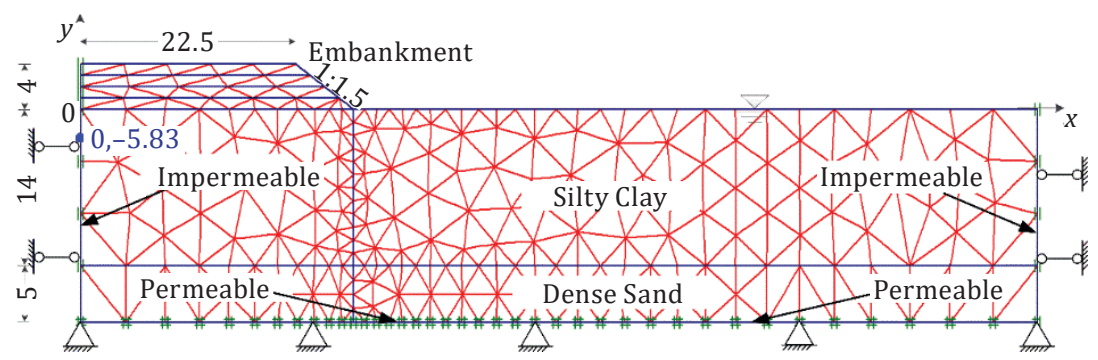

b) narrow embankment (embankment width - $12 \mathrm{~m}$ )

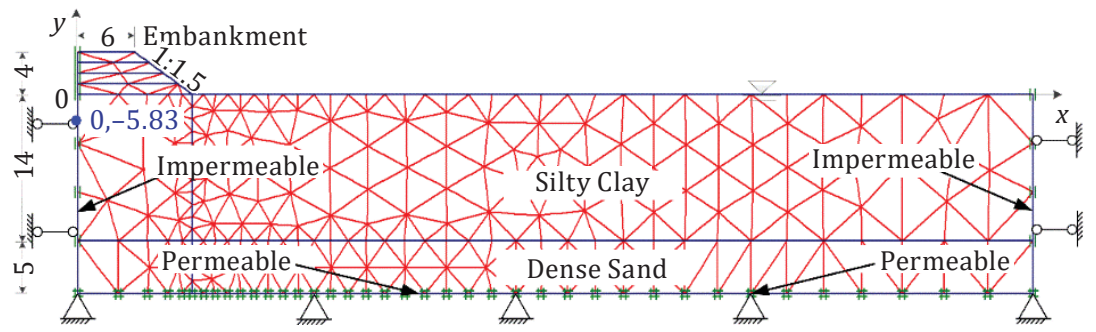

Note: units in $\mathrm{m}$.

Figure 1. Numerical model

\subsection{Constitutive model and material parameters}

As a special kind of soil, the constitutive model of soft soil should be carefully considered in numerical simulation to describe the mechanical properties scientifically. The Mohr-Coulomb model represents a firstorder approximation of soil behaviour, which is well developed and widely applied-using this model for a relatively quick and simple first analysis of the problem considered (Brinkgreve, 2002). Thus, this paper uses the Mohr-Coulomb model, an ideal elastic-plastic model embedded in PLAXIS software, for silty clay, dense sand, and embankment filling. Specific parameters of each soil layer are shown in Table 1 (Jiang et al., 2015).

As the permeability coefficient of silty clay is low, it is regarded as an undrained material. Meanwhile, the horizontal and vertical permeability coefficients of silty clay are different to consider the anisotropy. It was noted that with the consolidation of soft ground, silty clay is continuously compacted, and its permeability changes dynamically. 
In this paper, the permeability coefficient of silty clay is adjusted appropriately under Equation (1):

$$
\log \left(\frac{k}{k_{0}}\right)=\frac{\Delta e}{c_{k}},
$$

where $\Delta e=e-e_{0}, e_{0}$ is the initial void ratio; $e$ is the void ratio after consolidation; $k_{0}$ is the initial permeability coefficient; $k$ is the permeability coefficient after consolidation; $c_{k}$ is a constant, generally takes half of the initial void ratio, that is $c_{k}=0.5 e_{0}$ (Brinkgreve, 2002).

The dense sand and embankment filling are drained, the permeability coefficient is higher than that of silty clay, and $c_{k}$ is high enough. Namely, the permeability coefficient is assumed to be constant (Woods \& Rahim, 2008).

Table 1. Soil material parameters used in Mohr-Coulomb material model*

\begin{tabular}{|c|c|c|c|c|c|}
\hline & Name & Unit & $\begin{array}{l}\text { Dense } \\
\text { Sand }\end{array}$ & $\begin{array}{l}\text { Silty } \\
\text { Clay }\end{array}$ & Embankment \\
\hline $\begin{array}{l}\text { Type of material } \\
\text { behaviour }\end{array}$ & & - & Drained & Undrained & Drained \\
\hline Elastic modulus & $E$ & $\mathrm{MPa}$ & 60.0 & 1.50 & 13.0 \\
\hline Poisson ratio & $v$ & - & 0.33 & 0.32 & 0.3 \\
\hline $\begin{array}{l}\text { Unit weight above } \\
\text { phreatic level }\end{array}$ & $\gamma_{\text {unsat }}$ & $\mathrm{kN} / \mathrm{m}^{3}$ & 21.5 & 15.0 & 19.0 \\
\hline $\begin{array}{l}\text { Unit weight below } \\
\text { phreatic level }\end{array}$ & $\gamma_{\text {sat }}$ & $\mathrm{kN} / \mathrm{m}^{3}$ & 22.0 & 18.0 & 20.0 \\
\hline $\begin{array}{l}\text { Initial horizontal } \\
\text { permeability }\end{array}$ & $k_{O_{x}}$ & $\mathrm{~m} / \mathrm{d}$ & 1.0 & 0.0005 & 1.0 \\
\hline $\begin{array}{l}\text { Initial vertical } \\
\text { permeability }\end{array}$ & $k_{\mathrm{O}_{y}}$ & $\mathrm{~m} / \mathrm{d}$ & 1.0 & 0.0004 & 1.0 \\
\hline Cohesion & c & $\mathrm{kPa}$ & 1.0 & 30.0 & 31.0 \\
\hline Friction angle & $\varphi$ & $\circ$ & 38.0 & 18.0 & 25.0 \\
\hline Initial void ratio & $e_{0}$ & - & 0.5 & 1.4 & 0.5 \\
\hline $\begin{array}{l}\text { Permeability } \\
\text { change rate }\end{array}$ & $c_{k}$ & - & $1.0 \cdot 10^{15}$ & 0.7 & $1.0 \cdot 10^{15}$ \\
\hline
\end{tabular}

Note: * by Jiang et al. (2015)
Jinming Hu, Xing Qiv,

Yanjun Qiu

Analysis

of Settlement

Behaviour

of Soft Ground

under Wide

Embankment 


\subsection{Finite element mesh}

The high-precision 15-node triangular element containing 12 stress points is adopted to discretize the model, as shown in Figure 2. At the same time, the vertical line is intentionally added to the ground at the foot of the embankment slope when modelling to describe the lateral displacement distribution more accurately. Therefore, nodes are created on the line when the mesh is automatically generated. Finally, the mesh of the line is refined twice.

a) node

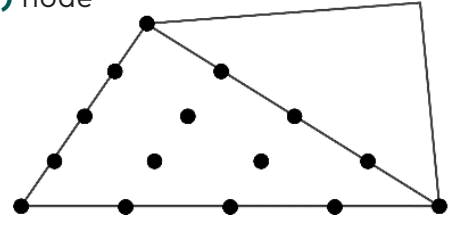

b) stress point

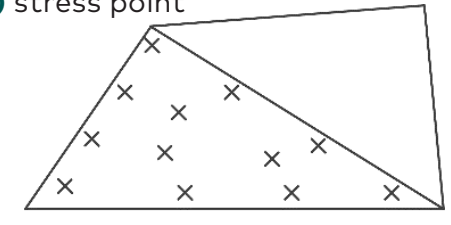

Figure 2. 15-node triangular elements (Brinkgreve, 2002)

\subsection{Boundary conditions and initial conditions}

Displacement boundary and consolidation boundary are set when using PLAXIS to carry out consolidation analysis of embankment on soft soil. The coordinate origin is set at the bottom of the embankment centreline. The horizontal direction to the right and vertical direction to the up are defined as the positive direction of the $x$-axis and $y$-axis, respectively. The dimensions of the wide and narrow embankments models along the $x$ direction are $100 \mathrm{~m}$ to facilitate the comparison of calculation results and avoid the influence of boundary conditions.

The left side of the model is the symmetrical axis. Its horizontal displacement is zero and impermeable. Therefore, the displacement boundary of horizontal constraint and vertical free and closed consolidation boundary are set. The exact boundaries are used on the right side of the model because there is no free outflow. The horizontal and vertical displacements at the bottom boundary of the model are constrained, and the consolidation boundary is open (i.e., permeable) because of the underlying dense sand. The upper boundary of the model is free.

The phreatic level coincides with the original ground surface, i.e., $y=0$. After creating the geometric model and dividing the finite element mesh, the initial stress state is generated, including the initial water pressure and the effective stress field. The initial effective stress field 
is calculated by " $K_{0}$-procedure". The numerical models of the wide and Jinming Hu, Xing Qiv, Yanjun Qiu narrow embankments are shown in Figure 1.

\subsection{Construction procedure}

Analysis

of Settlement

Behaviour

of Soft Ground

under Wide

Embankment

Considering JTG F10-2006 Technical Specification for Construction of Highway Subgrades (C C C C First Highway Engineering Co., Ltd, 2006), the embankment construction is filled and compacted layer by layer. The two types of embankments are divided into four horizontal layers. Each layer is $1.0 \mathrm{~m}$ thickness, each layer is filled for 20 days, and the construction interval is 40 days after each layer is filled. After the construction of the fourth-layer embankment is completed, the calculation is terminated when the excess pore pressure in the ground dissipates to below $1 \mathrm{kPa}$, i.e., the consolidation is almost complete. The detailed construction procedure is shown in Figure 3.

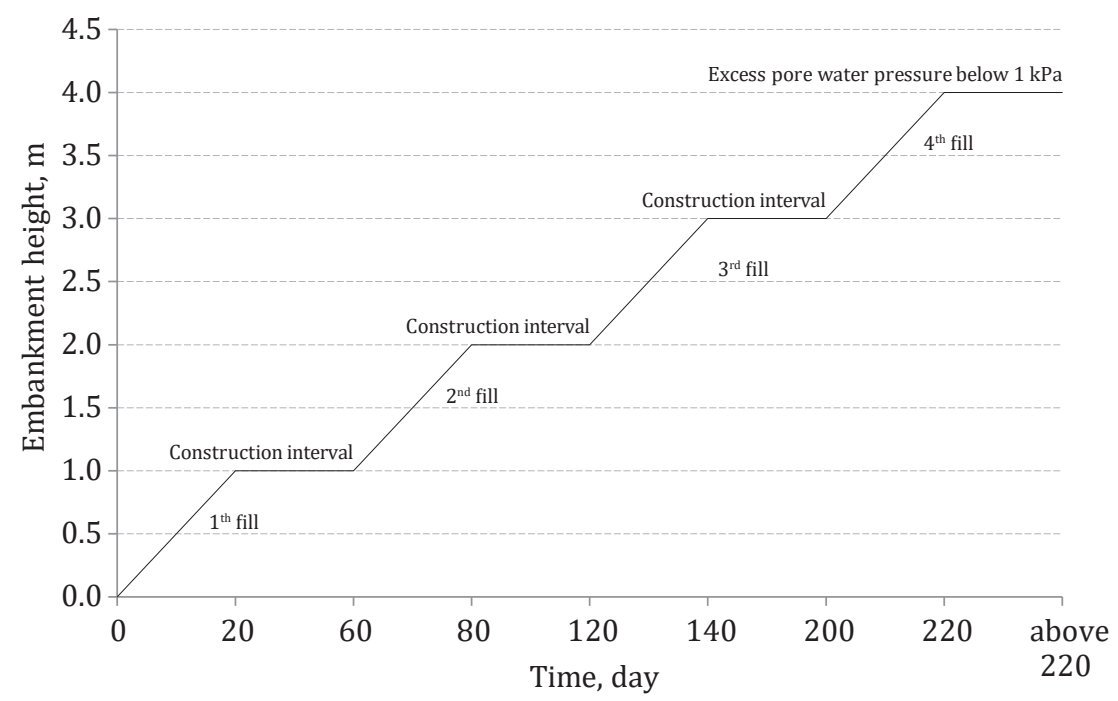

Figure 3. Construction procedure 


\section{Analysis and discussion of main calculation results}

\subsection{Stability}

Since stability is the precondition of subsequent calculation of settlement and deformation, the stabilities of wide and narrow embankments are analysed firstly. The shear strength reduction method, namely "Phi-c Reduction" in PLAXIS, is used to obtain the potential sliding surface and global safety factor. Figure 4 shows the dynamic evolution of the stability safety factor obtained by the "Phi-c Reduction" method with the whole construction process. It is concluded from Figure 4 that the stability safety factors of wide and narrow embankments are greater than 1.0 during the whole construction process, which indicates that the embankments are stable.

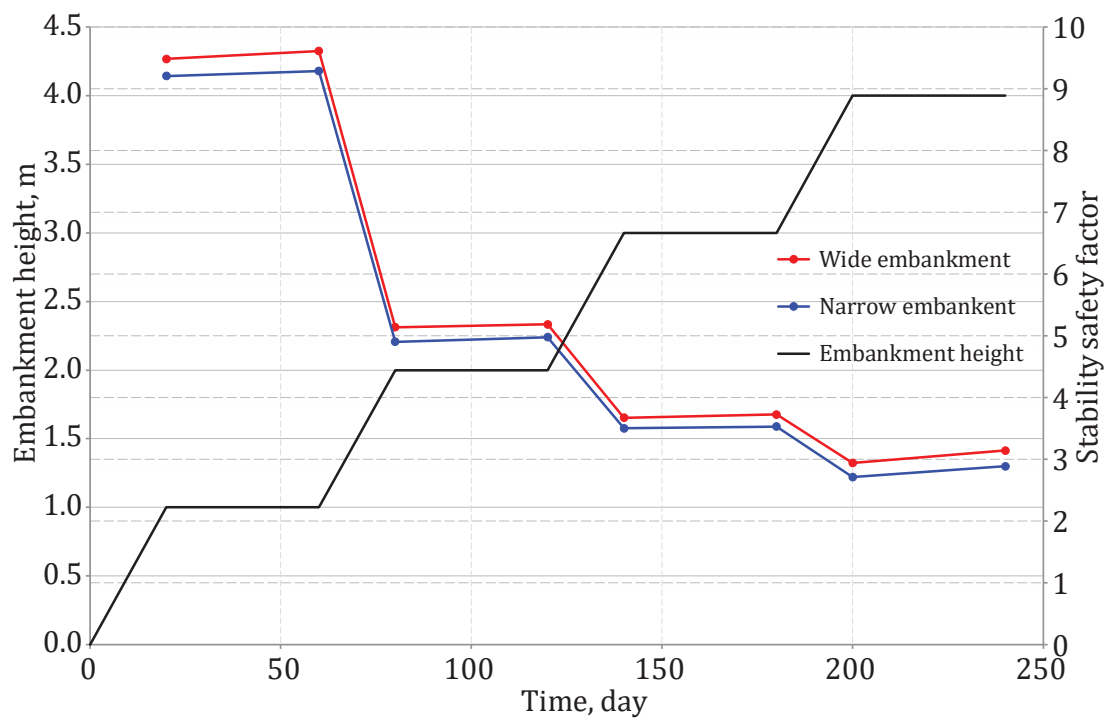

Figure 4. Stability safety factor 
Xin Jiang, Xiaoli Chen,

Yongguo Fu,

Hanyan Gu,

Jinming Hu, Xing Qiv,

Yanjun Qiu

Analysis

of Settlement

Behaviour

of Soft Ground

under Wide

Embankment

Figure 5 compares the ground surface settlements of wide and narrow embankments during and after construction. As Figure 5 shows:

1. The ground surface settlement of the wide embankment is roughly $\mathrm{W}$-shaped. The maximum settlement does not appear in the centreline of the embankment but near the foot of the embankment slope. As the increase of embankment filling height, the maximum settlement gradually moves to the centreline of the embankment. The macroscopic rule is entirely consistent with the field test results of Muar embankment (embankment width $88 \mathrm{~m}$ ) in Malaysia (Zhang, 1999). However, the ground surface settlement of narrow embankment is nearly V-shaped, and the maximum settlement always appears in the centreline of the embankment $(x=0)$.

2. For wide embankment, there is little difference between the maximum settlement of the ground surface and the settlement of the embankment centreline at the initial stage of construction. The difference between the two settlements gradually increases with the increase of embankment filling height. The maximum difference value is reached after the fourth layer embankment filling. As the development of ground post-construction consolidation, the difference between the two settlements begins to decrease. The difference between the two settlements reaches the smallest when the excess pore pressure in the ground dissipates to below $1 \mathrm{kPa}$. The preliminary analysis shows that because there is a one-dimensional compression zone in the middle of the wide embankment, the stress state is close to onedimensional compression, and the shear stress is almost zero. However, the shear displacement caused by the shear stress near the slopes on both sides of the embankment needs to be considered, further increasing the settlement. Therefore, the maximum settlement of soft ground does not appear on the centreline of the embankment under the wide embankment (Zhang, 1999). 
a) wide embankment

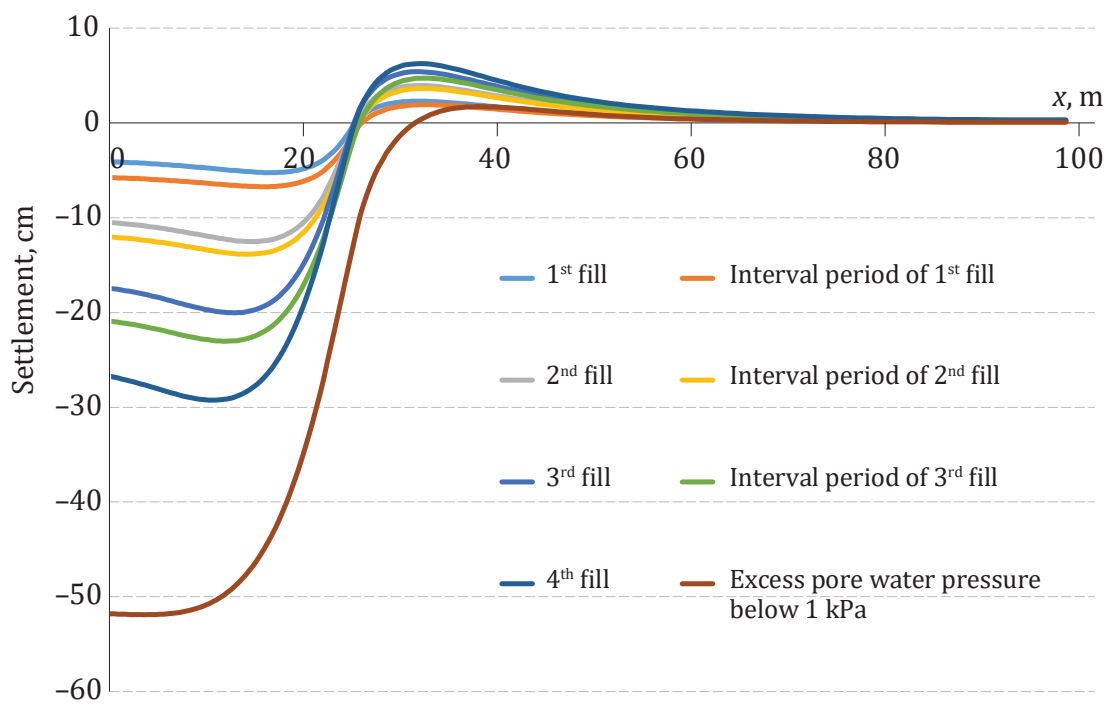

b) narrow embankment

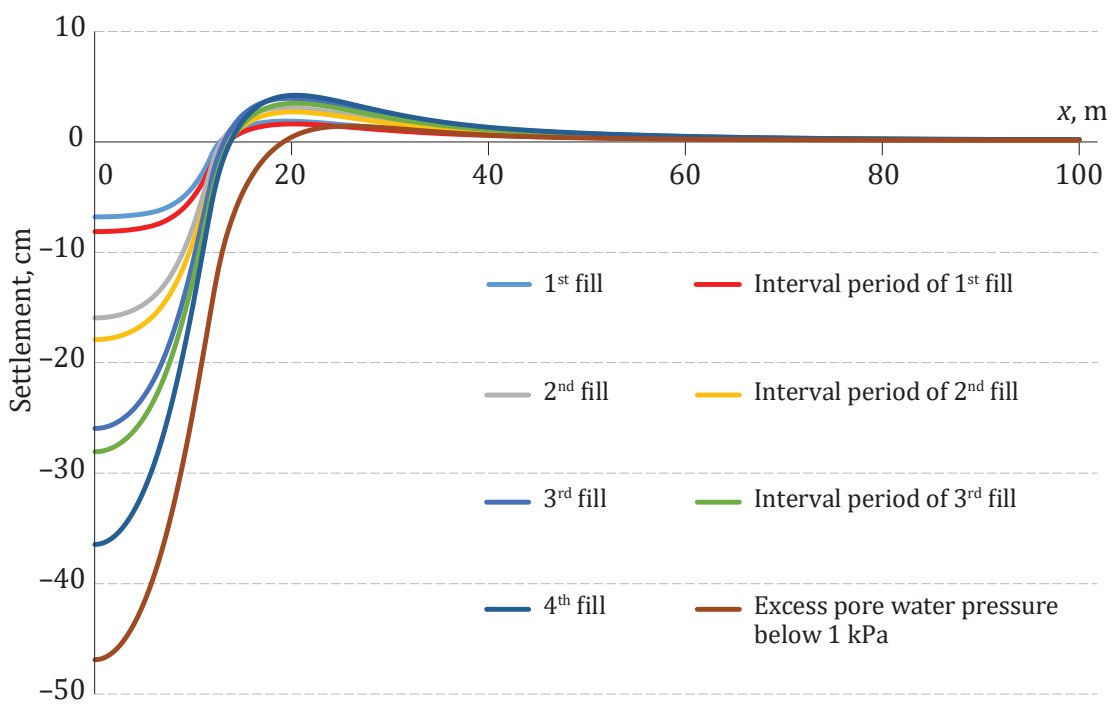

Figure 5. Settlement transverse distribution of ground surface 
Xin Jiang, Xiaoli Chen,

Yongguo Fu,

Hanyan Gu,

Jinming Hu, Xing Qiv,

Yanjun Qiu

Analysis

of Settlement

Behaviour

of Soft Ground

under Wide

Embankment centrifugal operation on $25 \mathrm{~g} \cdot \mathrm{t}$ geotechnical centrifuge, the deformation of natural ground during the construction period and subsequent 6-months preloading period and during 5-6 years in-service period (1.70 $\mathrm{m}$ soil column overloaded), and the total deformation are shown in Figure 6. The maximum and centreline settlements obtained by numerical simulation are relatively different from the centrifugal model test because of their different geometrical dimensions (soft soil thickness, embankment height, and embankment width), soil properties. However, the test results still make it clear that the maximum settlement of the natural ground does not appear in the centreline of the embankment during the construction period and post-construction, which is consistent with the macroscopic conclusions of numerical simulation in this paper.

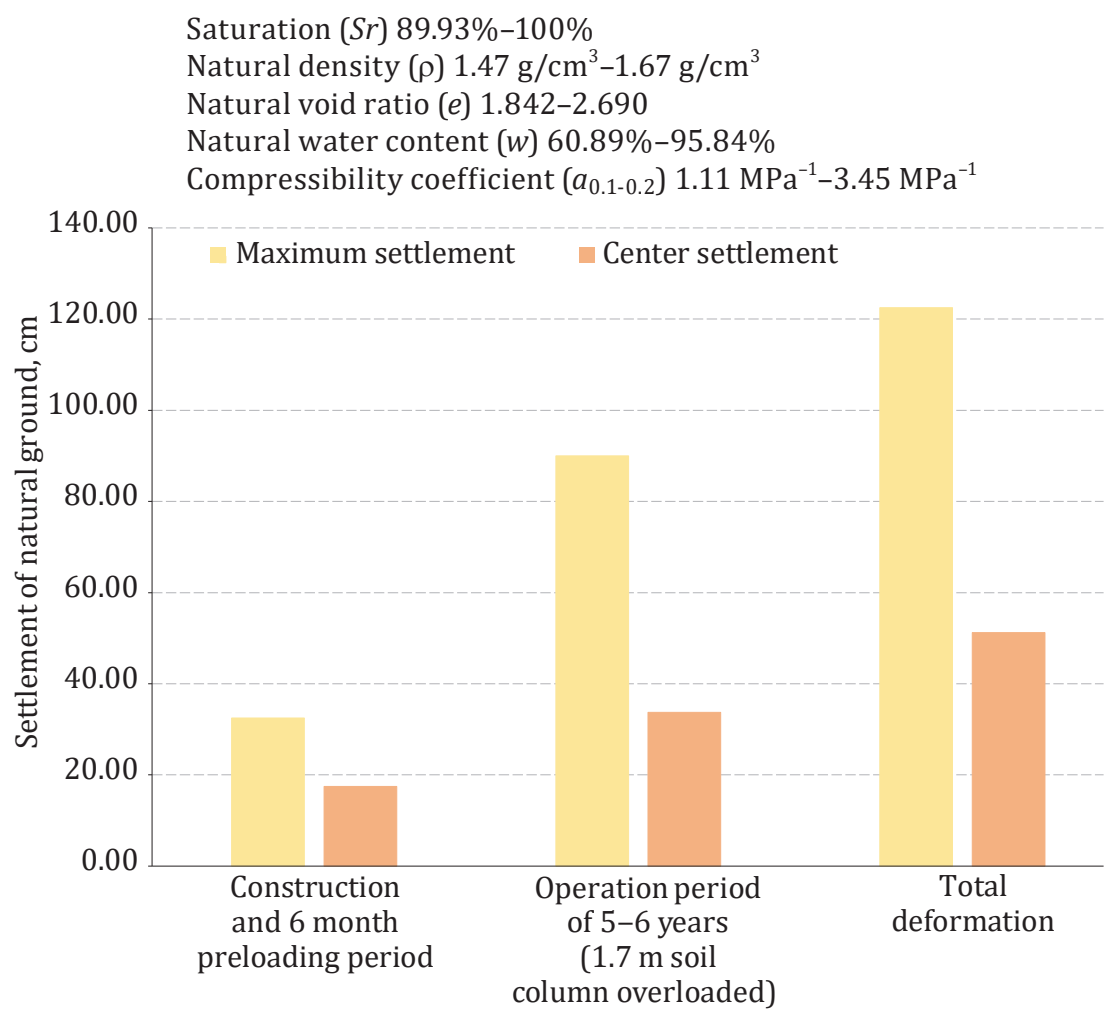

Figure 6. Settlement of natural soft ground obtained at different times from the centrifugal model test (Gan, 2006) 


\subsubsection{Embankment surface settlement}

Figure 7 displays the settlement transversal distribution of narrow and wide embankments surface after the fourth layer filling and when the excess pore pressure dissipates to below $1 \mathrm{kPa}$. It is shown from Figure 7:

1. The maximum settlement of the wide embankment at two specific times does not appear at the centreline of the embankment, but that of the narrow embankment appears there.

2. When the fourth layer embankment is completed, the maximum settlements of the wide and narrow embankments surface are $30.5 \mathrm{~cm}$ and $37.3 \mathrm{~cm}$, respectively. Furthermore, when the excess pore pressure dissipates to below $1 \mathrm{kPa}$, the maximum settlements of the two embankments are $53.0 \mathrm{~cm}$ and $47.5 \mathrm{~cm}$, respectively. The post-construction settlement of wide embankment is roughly twice that of the narrow embankment, $22.5 \mathrm{~cm}$ and $10.2 \mathrm{~cm}$, respectively.

\subsection{Lateral displacement at the foot of embankment slope}

The lateral displacement distribution of the ground section at the foot of the embankment slope with depth at different times is shown in Figure 8. It is indicated from Figure 8:

1. Whether wide or narrow embankment, the lateral displacement mainly distributes in the silty clay, and the displacement of the dense sand is minimal. As the increase of depth, the lateral

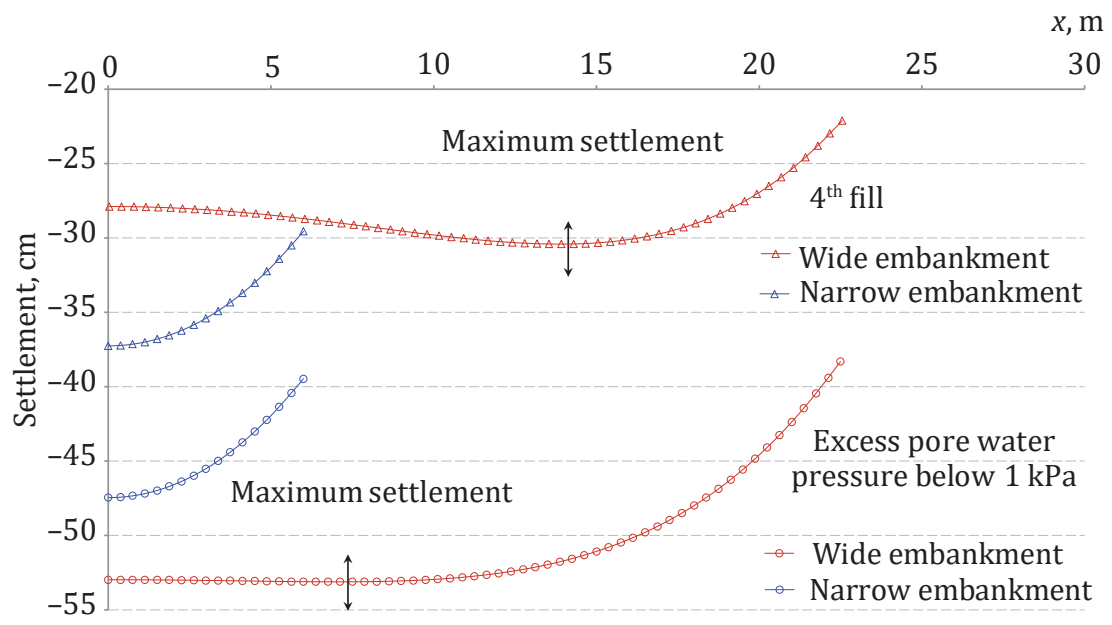

Figure 7. Settlement transversal distribution of embankment surface 
displacement in the silty clay increases firstly and then decreases, Jinming $H u$, Xing Qiv, Yanjun Qiu similar to the belly shape. The maximum lateral displacement occurs at a depth of one-third of the silty clay layer. The depth of the maximum lateral displacement of the wide embankment is slightly below that of the narrow embankment.

Analysis of Settlement Behaviour of Soft Ground under Wide Embankment

a) wide embankment Lateral displacement, $\mathrm{cm}$

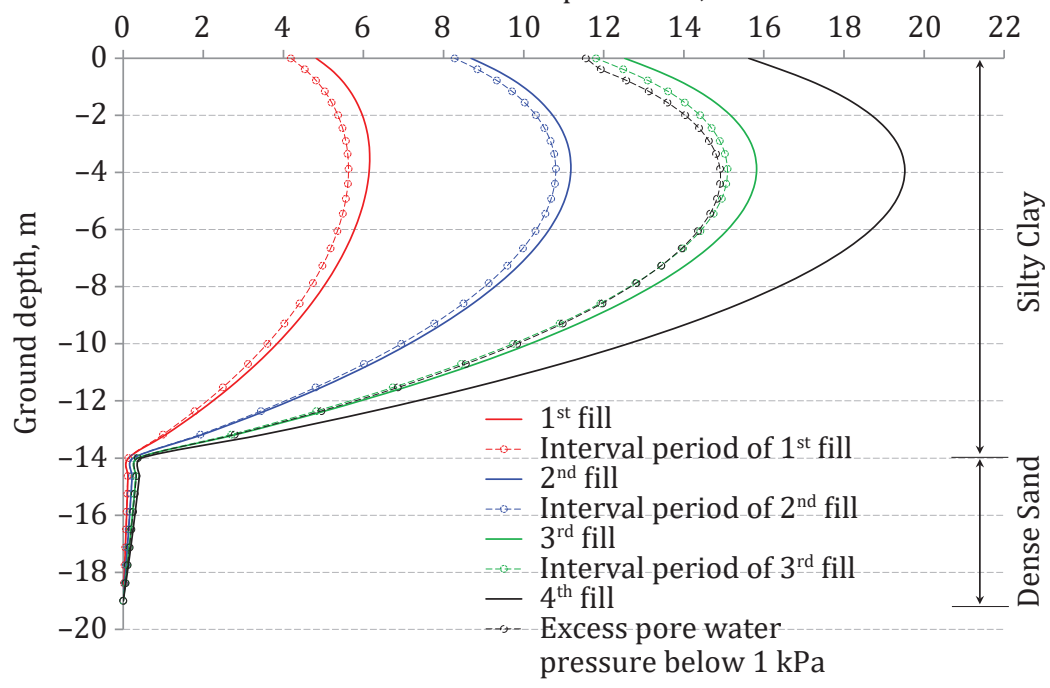

b) narrow embankment

Lateral displacement, $\mathrm{cm}$

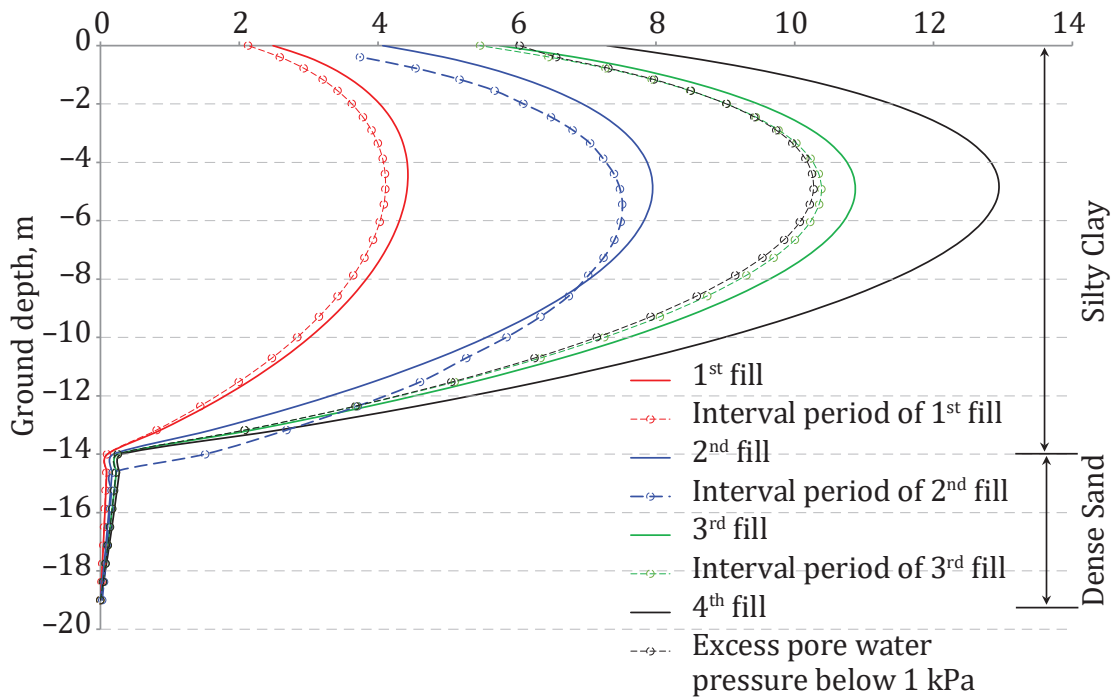

Figure 8. Lateral displacement distribution of ground at the foot of embankment slope 
2. The lateral displacements at the foot of wide and narrow embankments slope increase with embankment filling height. The lateral displacement at each stage of the wide embankment is larger than that of the narrow embankment. When the fourth layer embankment is completed, the lateral displacement reaches the maximum value. The lateral displacements of the wide and narrow embankments shrink when the post-construction excess pore pressure in the ground dissipates to below $1 \mathrm{kPa}$. The lateral displacement of the wide embankment shrink is larger than that of the narrow embankment (the shrinkage of lateral displacement of the wide embankment is about $5 \mathrm{~cm}$, and that of the narrow embankment is below $3 \mathrm{~cm}$ ).

3. The lateral displacements of the wide and narrow embankments are slightly reduced at the end of the construction interval compared to the end of each layer of filling in the silty clay layer.

\subsection{Excess pore pressure of ground}

Figure 9 shows the variation of excess pore pressure with time at the exact location in soft ground with wide and narrow embankments. The calculation points are taken from a specific location of soft ground on the centreline of the embankment, and the coordinates are $(0,-5.83)$, as shown in Figure 1. It illuminates that the excess pore pressure rises during the filling period and decreases slightly during the construction interval period, showing a unique serrated shape

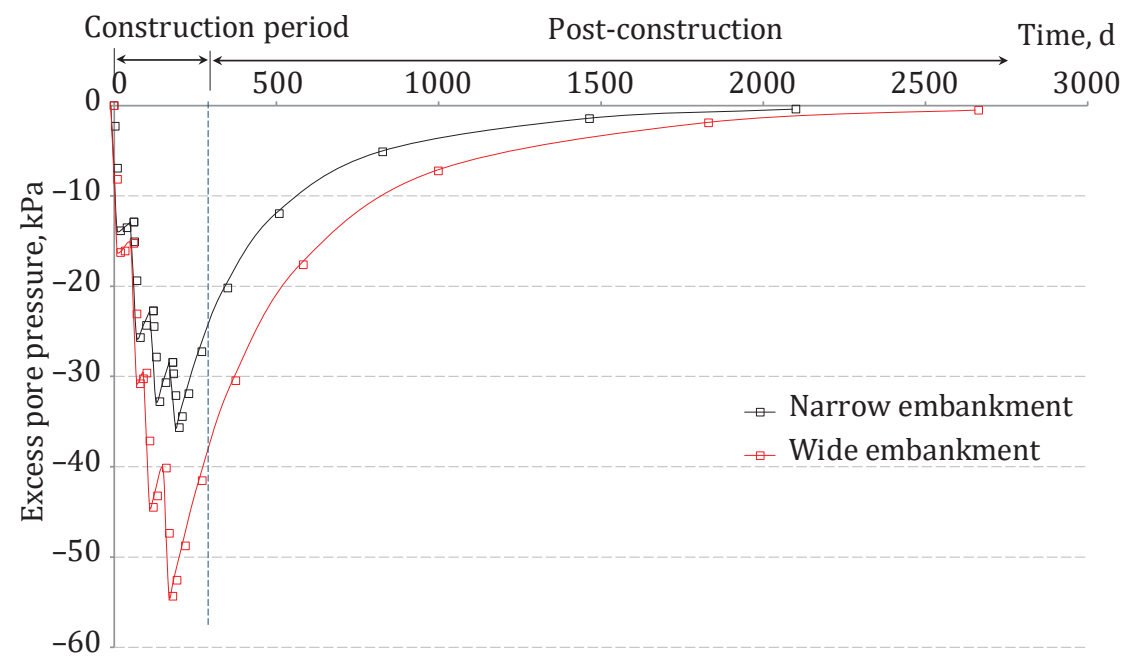

Figure 9. Variation of excess pore pressure 

the narrow embankment. At the same time, it takes longer for the excess pore pressure of wide embankment to dissipate to below $1 \mathrm{kPa}$ than that of the narrow embankment (2698 days for wide embankment and 2100 days for narrow embankment), namely, the consolidation time for wide embankment is longer.

Figure 10 shows the distribution of excess pore pressure in soft ground when the fourth layer of the narrow and wide embankments is constructed. The maximum excess pore pressure in the soft ground mainly distributes in the middle of the silty clay at the centreline of the embankment. It gradually decreases like bubbles from the centreline of the embankment to the outside.

\subsection{Influence of elastic modulus of soft soil on wide embankment vertical settlement}

Based on the numerical model of the wide embankment mentioned above, other parameters remain the same. The settlement of ground is calculated when the elastic modulus of silty clay is $1.5 \mathrm{MPa}, 3.0 \mathrm{MPa}$, 4.5 $\mathrm{MPa}$, 6.0 $\mathrm{MPa}$, 7.5 $\mathrm{MPa}$ and 9.0 $\mathrm{MPa}$, respectively. The concrete

a) wide embankment

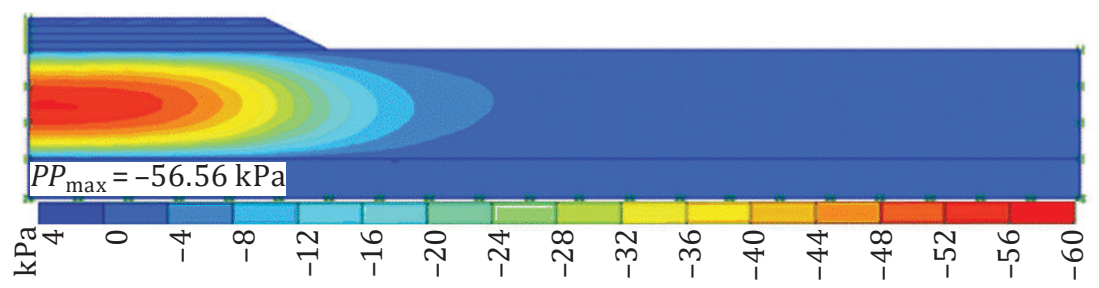

b) narrow embankment

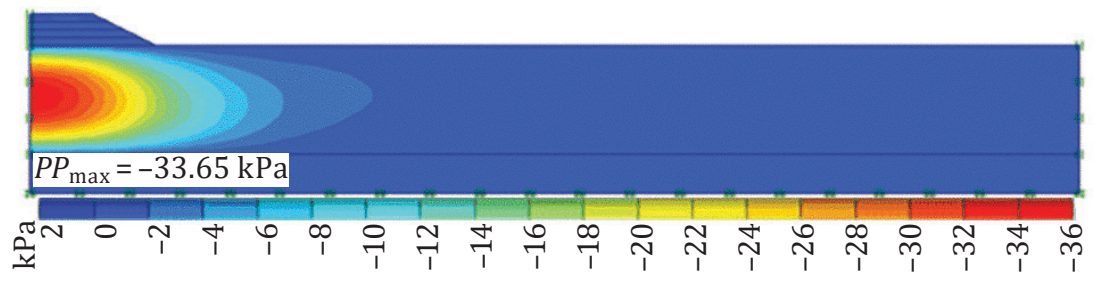

Figure 10. Distribution of excess pore pressure 
results are shown in Figure 11. It indicates that with the increase of elastic modulus of silty clay (equivalent to the increase of ground improvement degree in practical engineering), the ground surface settlement decreases. The location of maximum settlement gradually

a) completion of embankment filling on the $4^{\text {th }}$ layer

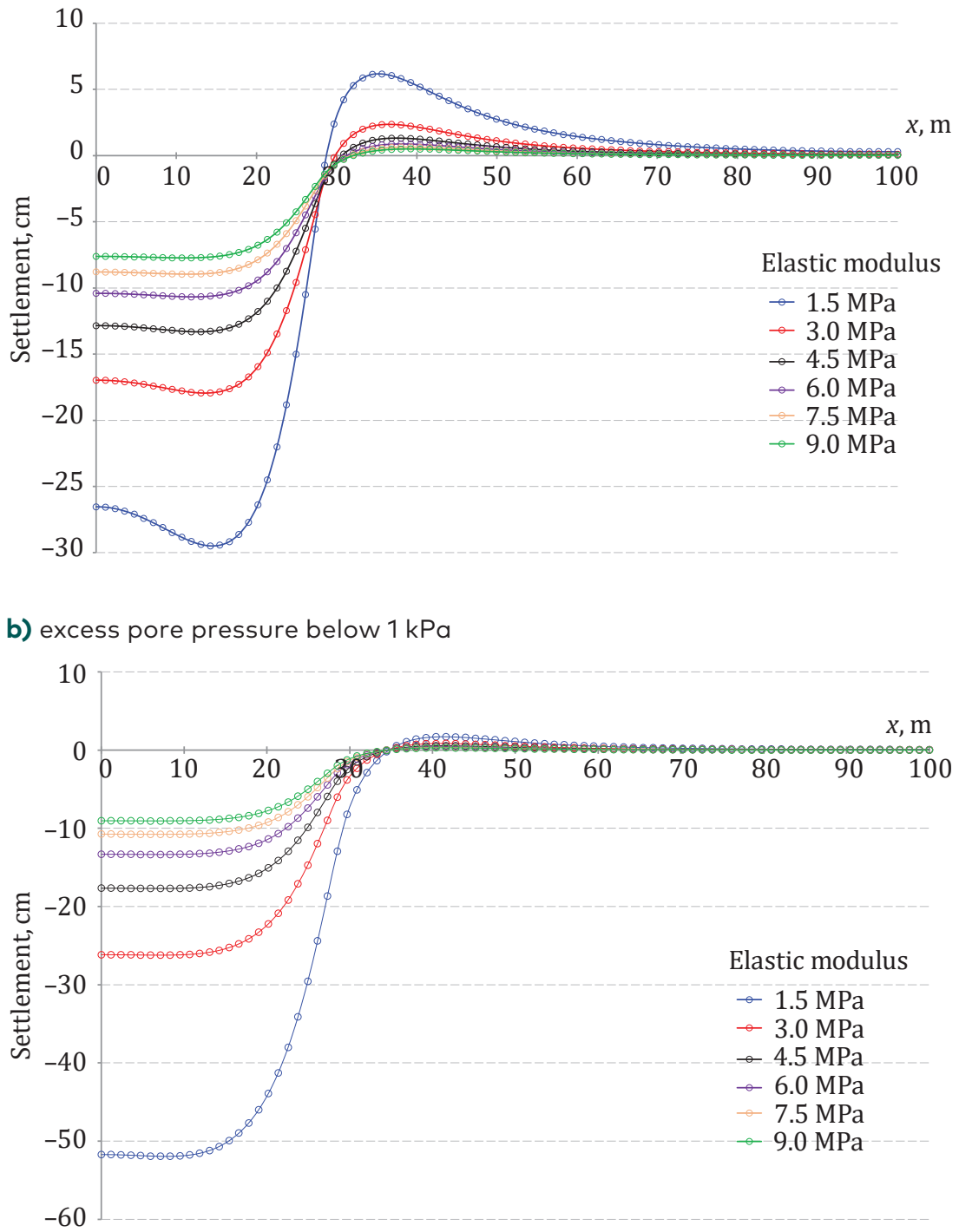

Figure 11. Relationship between ground settlement and elastic modulus of soft soil 
moves from near the foot of the embankment slope to the centreline of the embankment. The $\mathrm{W}$-shaped deformation of the ground surface settlement curve with a wide embankment becomes more relaxed, but its macroscopic settlement rule is still the same.

The macroscopic conclusions obtained in Figure 11 were confirmed by Huang and Zhang (2007). Huang and Zhang (2007) conducted field deformation observation of section $\mathrm{K} 60+430$ of the $9^{\text {th }}$ contract section of Xinxiang to Zhengzhou of Beijing-Zhuhai Expressway. The stratum is mainly silty clay and silt, and the filling height is $8.0 \mathrm{~m}$. The total width of the embankment surface is $99.0 \mathrm{~m}$, treated by mixing piles with a depth of $8.5 \mathrm{~m}$ and spacing of $1.2 \mathrm{~m}$. Figure 12 shows the settlement variation rule of the ground cross-section with the increase of embankment filling height. It clarifies that even if the soft ground with a wide embankment is treated by mixing piles, the elastic modulus of soft soil has been greatly improved. However, the $\mathrm{W}$-shape macroscopic settlement rule of the ground surface is still the same. Therefore, it indicates that the W-shape settlement macroscopic rule of the wide embankment is not affected by whether the soft ground is treated and the treatment degree.

At the same time, it is noticed that the settlement is rapidly reduced with the increase of elastic modulus. It indicates that ground settlement

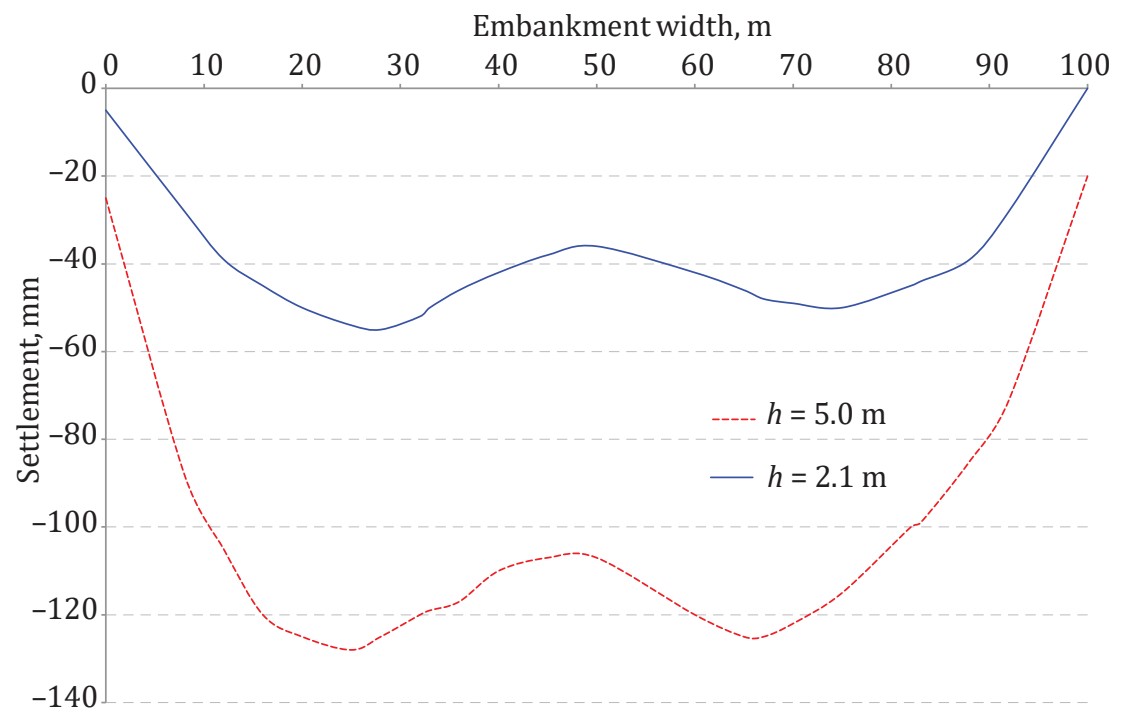

Note: GetData Graph Digitizer software is used to draw from Huang and Zhang (2007)

Figure 12. In-situ settlement monitoring results of $\mathrm{K} 60+430$ section of Xinxiang-Zhengzhou No. 9 section of Beijing-Zhuhai Expressway (mixing pile for ground treatment)

\section{Yanjun Qiu}

Analysis of Settlement Behaviour of Soft Ground under Wide Embankment 
THE BALTIC JOURNAL

OF ROAD

AND BRIDGE

ENGINEERING

2021/16(4)

of wide embankment is effectively reduced after ground treatment. However, when the ground treatment degree reaches a certain level, it is uneconomic and technically unreasonable to further improve the soft ground treatment degree to reduce the wide embankment settlement. This research result is entirely consistent with the conclusion of finite element analysis by Mao and Qiu (2012).

\section{Design considerations for a wide embankment on soft ground}

The above analysis fully shows that the settlement of wide embankment is approximately equal within a specific range near the centreline of the embankment. There is a one-dimensional compression zone, and with the increase of embankment filling height, the range of the one-dimensional compression zone decreases gradually. Design considerations for a wide embankment on soft ground in practical engineering are proposed as follows:

1. For wide and narrow embankments of the same height, the ground treatment of wide embankment should be higher than that of the narrow embankment. The ground treatment degree of the wide embankment can be reduced appropriately in the range of a one-dimensional compression zone.

2. The construction monitoring scheme can be adjusted under the settlement behaviour of soft ground under the wide embankment. For example, the monitoring point of a ground surface settlement should also be arranged near the foot of the embankment slope beside the centreline of the embankment traditionally.

\section{Conclusions}

1. The settlement curves of the ground surface and embankment surface of the wide embankment are roughly W-shaped, and the maximum settlement occurs near the foot of the embankment slope. However, that of the narrow embankment is V-shaped, and the maximum settlement is always at the centreline of the embankment. At the same time, the post-construction settlement of the wide embankment surface is about twice that of the narrow embankment surface.

2. The lateral displacements of wide and narrow embankments are mainly distributed in the soft soil, showing a similar belly shape. 
Xin Jiang, Xiaoli Chen,

Yongguo Fu,

Hanyan Gu,

Jinming Hu, Xing Qiv,

Yanjun Qiu

The lateral displacements shrink when the post-construction

Analysis consolidation of the ground is nearly completed. The maximum lateral displacements are about one-third of the depth of the silty clay, and the depth of the maximum lateral displacement of the wide embankment is slightly below that of the narrow of Settlement Behaviour of Soft Ground under Wide Embankment embankment. Meanwhile, the lateral displacement of the wide embankment at each corresponding stage is larger than that of the narrow embankment.

3. The maximum excess pore pressure in the soft ground of wide and narrow embankments distributes in the middle of the silty clay at the centreline of the embankment in each stage. It decreases gradually like bubbles from the centreline of the embankment to the outside. At the same time, the excess pore pressure of the wide embankment ground is much higher than that of narrow embankment during construction, so it takes longer to consolidate after construction.

4. With the increase of embankment height and elastic modulus of soft soil, the maximum settlement of the wide embankment ground gradually moves to the centreline of the embankment. However, the macroscopic settlement rule of the $\mathrm{W}$-shape is still the same.

\section{Acknowledgements}

The authors thank the Sichuan Science and Technology Program and Key Laboratories Open Engineering Practice Program to Undergraduates of SWJTU for funding this work.

\section{Funding}

This work was supported by the Sichuan Science and Technology Program under Grant No. 2019YFS0492 and Key Laboratories Open Engineering Practice Program to Undergraduates of SWJTU under Grant No. ZD201918034.

\section{REFERENCES}

Allersma, H. G. B., Ravenswaay, L., \& Vos, E. (1994). Investigation of road widening on soft soils using a small centrifuge. Transportation Research Record, (1462), 47-53. 
THE BALTIC JOURNAL

OF ROAD

AND BRIDGE

ENGINEERING

$2021 / 16(4)$

Brinkgreve, R. B. J. (2002). PLAXIS Version 8 Reference Manual. Delft University of Technology \& PLAXIS b. v., The Netherlands.

C C C C Second Highway Consultants Co., Ltd. (2015). Specifications for Design of Highway Subgrades (JTG D30-2015). Beijing, China: China Communications Press Co. Ltd., 64-70. (in Chinese)

C C C C First Highway Engineering Co., Ltd. (2006). Technical Specification for Construction of Highway Subgrades (JTG F10-2006). Beijing, China: China Communications Press Co. Ltd., 10-11. (in Chinese)

C C C C First Highway Consultants Co., Ltd. (2013). Technical Guidelines for Design and Construction of Highway Embankment on Soft Ground (JTG/T D31-02-2013). Beijing, China: China Communications Press Co. Ltd., 45-56. (in Chinese)

Chai, J. C., \& Bergado, D. T. (1993). Some techniques for finite element analysis of embankments on soft ground. Canada Geotechnical Journal, 30(4), 710-719. https://doi.org/10.1139/t93-060

Chen, J. F., \& Shi, Z. M. (2006). Analysis of the interaction between broad embankment and its subsoil. Journal of Highway and Transportation Research and Development, 23(2), 6-9. https://doi.org/10.3969/j.issn.1002-0268.2006.02.002 (in Chinese)

Chen, J. F., Shi, Z. M., \& Shen, M. R. (2003). FEM simulation of settlement patterns of broad embankment. Journal of Highway and Transportation Research and Development, 20(4), 23-25. https://doi.org/10.3969/j.issn.1002-0268.2003.04.007 (in Chinese)

Gan, S. J. (2006). Research into settlement of super wide embankment on soft soil ground. Subgrade Engineering, (3), 16-19. https://doi.org/10.3969/j.issn.1003-8825.2006.03.007 (in Chinese)

Gates, R. H. (1968). Discussion of analysis of embankment stress and deformation. Journal of Soil Mechanics and Foundations Division, 36(3), 60-63.

Han, J., Oztoprak, S., Parsons, R. L. \& Huang, J. (2007). Numerical analysis of foundation columns to support widening of embankments. Computers and Geotechnics, 34(6), 435-448. https://doi.org/10.1016/j.compgeo.2007.01.006

Highway Bureau of the Ministry of Transport of the People's Republic of China \& C C C C First Highway Consultants Co., Ltd. (2014). Techical Standard of Highway Engineering (JTG B01-2014). Beijing, China: China Communications Press Co. Ltd., 17-20. (in Chinese)

Huang, S. G., \& Zhang, X. W. (2007). Study on settlement behavior of super wide subgrade. Chinese Journal of Rock Mechanics and Engineering, 26(s2), 4079-4083. (in Chinese)

Jiang X., Jiang Y., Wu C. Y., Wang W. Q., Geng J. Y., \& Qiu Y. J. (2020). Numerical analysis for widening embankments over soft soils treated by PVD and DJM columns. International Journal of Pavement Engineering, 21(3), 267-279. https://doi.org/10.1080/10298436.2018.1461869

Jiang, X., Chen, X. L., Xiao, H., Zhang, Q. S., \& Qiu, Y. J. (2019). Typical cases and identification methods for newly-built wide embankments over soft soil foundations. Journal of Transportation Engineering and Information, 17(1), 59-66. https://doi.org/10.3969/j.issn.1672-4747.2019.01.010 (in Chinese) 
Jiang, X., Jiang, Y., Liang, X. J., Wu, C. Y., \& Qiu, Y. J. (2015). Numerical simulation on deformation behaviors for widened expressway embankment over soft ground. Journal of Railway Science and Engineering, 12(5), 1039-1046. https://doi.org/10.19713/j.cnki.43-1423/u.2015.05.009 (in Chinese)

Jiang, X., Qiu, Y. J., \& Zhou, C. (2006). On the settlement behavior of soft foundation under embankment loading. Hydrogelogy \& Enineering Geology, (1), 111-114. https://doi.org/10.3969/j.issn.1000-3665.2006.01.029 (in Chinese)

Lu, W., Miao, L., Wang, E., Zhang, J., Zhang, Y., \& Wang, H. (2020). A case study on geogrid-reinforced and pile-supported widened highway embankment. Geosynthetics International, 27 (3), 261-274.

https://doi.org/10.1680/jgein.19.00024

Luan, R. G., Wang, L. J., \& Li, Y. (2014). Research on settlement characteristics of wide embankment composite foundation of high-speed railway station. Journal of the China Railway Society, 36(10), 95-101. https://doi.org/10.3969/j.issn.1001-8360.2014.10.016 (in Chinese)

Mao, C., \& Qiu, Y. J. (2002). Numerical analysis of consolidation settlement of stabilised soft ground in super wide embankment. Northeastern Highway, 25(3), 31-33. (in Chinese)

Shen, Y. M. (1992). Soft ground design of super wide embankment in Guangzhou Metro Depot. Subgrade Engineering, (2), 16-19. (in Chinese)

Trong, H. D., Phi, H. D., Sy, D. N. \& Minh, H. H. (2016). Review on treatment methods of soft soil subgrade. International Journal of Civil Engineering and Machinery Manufacture, 1(1), 28-30.

van Meurs, A. N. G., van Den Berg, A., Venmans, A. A. M., Zwanenburg, C. Z., \& Van, M. A. (1999). Embankment widening with the gap-method. In Twelfth European Conference on Soil Mechanics and Geotechnical Engineering (Proceedings) the Netherlands Society of Soil Mechanics and Geotechnical Engineering; Ministry of Transport, Public Works and Water Management; AP van den Berg Machinefabriek; Fugro NV; GeoDelft; Holland Railconsult (No. Volume 2).

Wang, J. L., \& Xiong, Z. Y. (1992). Discussion on large area soft foundation reinforcement of Shenzhen airport ground and parking apron, Subgrade Engineering, (3), 60-70. (in Chinese)

Woods, R., \& Rahim, A. (2008). CRISP2D Technical Reference Manual. The CRISP Consortium Limited.

Zhang, L. M. (1999). Settlement patterns of soft soil foundations under embankments. Canada Geotechnical Journal, 36(4), 774-781.

https://doi.org/10.1139/t99-031
Xin Jiang, Xiaoli Chen,

Yongguo $\mathrm{Fu}$,

Hanyan Gu,

Jinming Hu, Xing Qiv,

Yanjun Qiu

Analysis

of Settlement

Behaviour

of Soft Ground

under Wide

Embankment 